\title{
MAMMALIAN LINEAGES IN THE PALEOGENE OF WYOMING-MONTANA: RATES OF CHANGE, SPECIES LONGEVITIES, AND MODES OF SPECIATION
}

\author{
GINGERICH*, Philip D., Museum of Paleontology, University of Michigan, Ann Arbor, MI \\ 48109-1079 U.S.A.; GUNNELL, Gregg F., Museum of Paleontology, University of \\ Michigan, Ann Arbor, MI 48109-1079 U.S.A.
}

The Clarks Fork Basin in northwestern Wyoming contains a thick stratigraphic section of Paleocene and Eocene fluvial sediments, parts of which are exceptionally complete and very important for quantitative study of mammalian evolution. The 1520-2270 m interval of the early Eocene in the Clarks Fork Basin, representing about $2 \mathrm{~m}$.y. of evolutionary time, has been sampled on a scale of $10 \mathrm{~m} \approx 27,000$ years.

Rates of morphological change can be calculated from measurements of tooth size for successive large samples in this section. These are quantified in terms of proportional change in standard deviation units, with time in generations. Fig. 1 (lower left) shows the distribution of 548 nonzero rates for the dawn horse Hyracotherium grangeri lineage plotted on log-log axes. The distribution has a robust maximum likelihood slope of -0.923 with a bootstrapped confidence interval ranging from -0.798 to -1.041 : the observed interval includes -1.00 expected for a stabilizing process (stasis), but excludes -0.50 expected for random change and 0.00 expected for a process like directional selection. Extrapolation indicates $H$. grangeri changed at an intrinsic rate of 0.23 standard deviations per generation on a time scale of one generation (95\% CI ranges from 0.06 to 0.87 ). This and other examples known to date suggest intrinsic rates for lineages in stasis are indistinguishable from (no lower than) intrinsic rates for artificially selected directional change in laboratory selection experiments. Consequently, significant differences in net change observed over time cannot be explained intrinsically but must be due to extrinsic factors.

Species durations can be estimated to the nearest $0.1 \mathrm{~m}$.y. for 46 well sampled lineages (open histogram in Fig. 2, lower right, cross-hatched where overlapping black Poisson distribution with same half-life $\lambda$ ). Median duration is $0.5 \mathrm{~m} . \mathrm{y}$., modal duration is $0.3 \mathrm{~m} . \mathrm{y}$. Note excess of both short- and long-duration species, indicating durations are neither independent of each other nor an intrinsic property of species. Here again, change and speciation, fast or slow, are probably driven by environmental factors extrinsic to the species themselves.

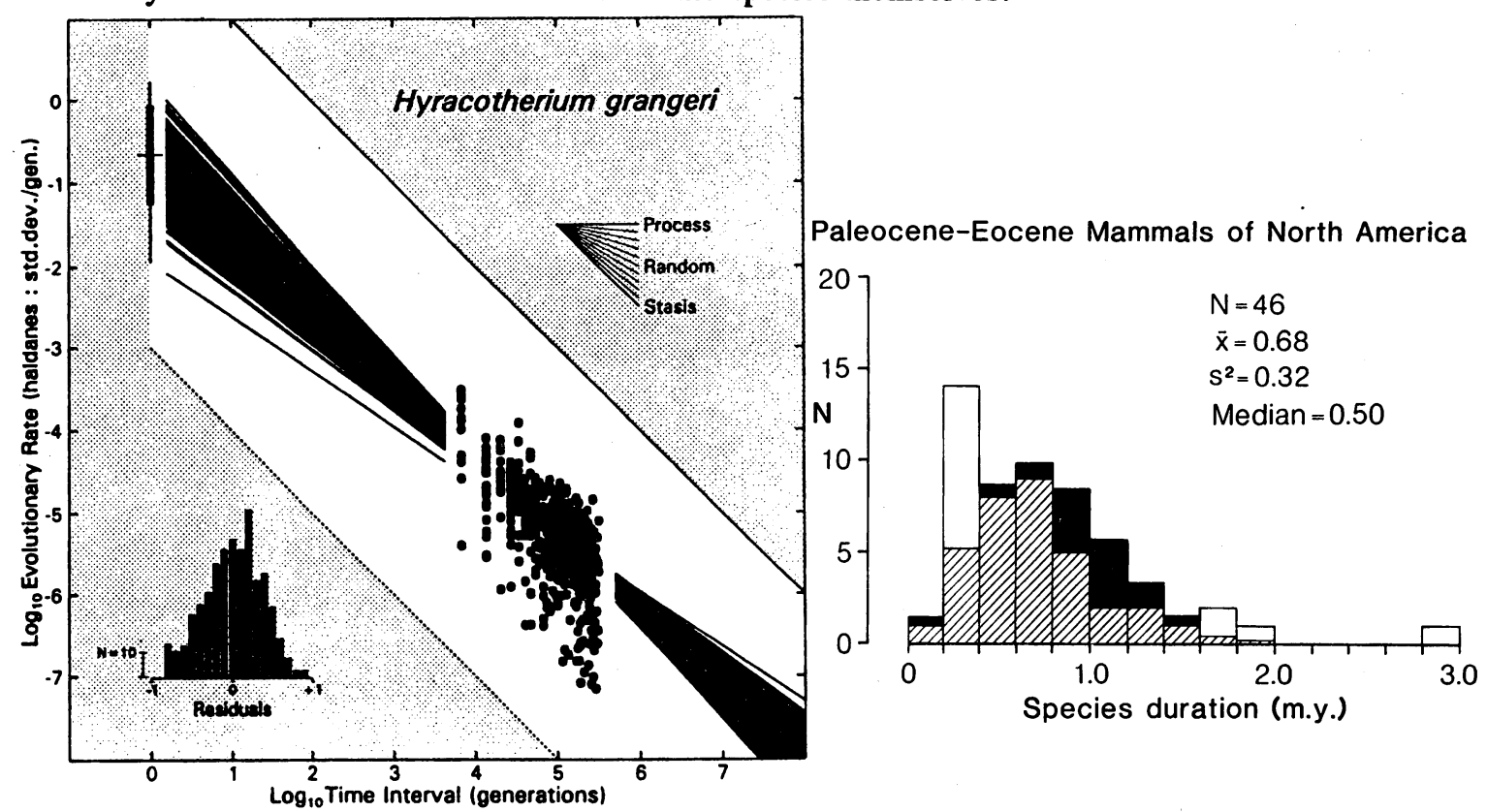

